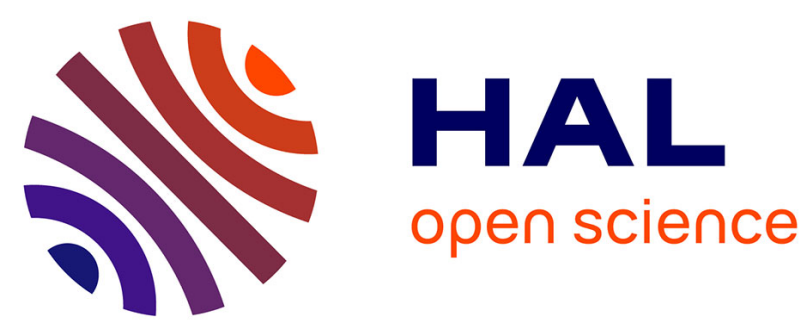

\title{
Differential risk of severe infection in febrile neutropenia among children with blood cancer or solid tumor
}

Mathilde Delebarre, Rodrigue Dessein, Marion Lagrée, Françoise Mazingue, Hélène Sudour-Bonnange, Alain Martinot, François Dubos

\section{- To cite this version:}

Mathilde Delebarre, Rodrigue Dessein, Marion Lagrée, Françoise Mazingue, Hélène Sudour-Bonnange, et al.. Differential risk of severe infection in febrile neutropenia among children with blood cancer or solid tumor. Journal of Infection, 2019, 79, pp.95 - 100. 10.1016/j.jinf.2019.06.008 . hal-03487903

\section{HAL Id: hal-03487903 \\ https://hal.science/hal-03487903}

Submitted on 20 Dec 2021

HAL is a multi-disciplinary open access archive for the deposit and dissemination of scientific research documents, whether they are published or not. The documents may come from teaching and research institutions in France or abroad, or from public or private research centers.
L'archive ouverte pluridisciplinaire HAL, est destinée au dépôt et à la diffusion de documents scientifiques de niveau recherche, publiés ou non, émanant des établissements d'enseignement et de recherche français ou étrangers, des laboratoires publics ou privés.

\section{(ㅇ)(1) $\$$}

Distributed under a Creative Commons Attribution - NonCommerciall 4.0 International 


\section{Differential risk of severe infection in febrile neutropenia among children with blood cancer or solid tumor}

Mathilde Delebarre, ${ }^{\mathrm{a}, \mathrm{b}, \mathrm{c}}$ Rodrigue Dessein,,${ }^{\mathrm{a}, \mathrm{d}}$ Marion Lagrée, ${ }^{\mathrm{c}}$ Françoise Mazingue, ${ }^{\mathrm{e}}$ Hélène Sudour-Bonnange, ${ }^{\mathrm{f}}$ Alain Martinot, ${ }^{\mathrm{a}, \mathrm{b}, \mathrm{c}}$ and François Dubos,, a,b,c*

\section{Affiliations:}

${ }^{a}$ Univ. Lille, CHU Lille, F-59000, Lille, France; ${ }^{\mathrm{b}}$ EA2694, Public Health, Epidemiology and Quality of Care, Lille, France; F-59000, Lille, France; ${ }^{\mathrm{C}} \mathrm{CHU}$ Lille, Pediatric Emergency Unit \& Infectious Diseases, F-59000 Lille, France; ${ }^{\mathrm{d}} \mathrm{CHU}$ Lille, Microbiology Unit, PathologyBiology Center, F-59000 Lille, France; ${ }^{\mathrm{e}} \mathrm{CHU}$ Lille, Pediatric Hematology Unit, F-59000

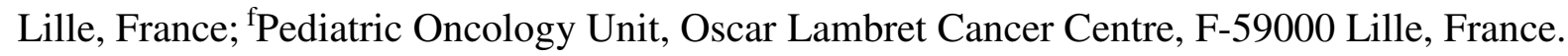
*Correspondance to: Dubos François, Hôpital R. Salengro, CHRU Lille, 2 avenue Oscar Lambret, 59000 Lille, France. Phone: +33-3-20-44-55-75; Fax: +33-3-20-44-47-19; E-mail: francois.dubos@chru-lille.fr

Funding: none

Conflict of interests: MD, RD, ML, FM, HD have no conflict of interest; AM has had appointments for lecture and consultancy/advice (GSK vaccines, Pfizer), and invitations to ESPID meetings (GSK vaccines, Pfizer); FD has been invited for a lecture without fees at the national pediatric primary-care meeting (AFPA) 2017 by GSK vaccines. He has received fees from Biocodex for two lectures in 2017 pediatric meetings.

Abstract word count: 200; Text word count: 2323; Tables: 3; Figures: 1 


\section{Abstract}

2 Objective: To describe and analyze the differences between infections in children with febrile

3 neutropenia $(\mathrm{FN})$ treated for solid tumor or blood cancer.

4 Methods: A prospective study included all episodes of FN in children from April 2007 to

5 April 2016 in 2-pediatric cancer centers in France. Medical history, clinical and laboratory

6 data available at admission and final microbiological data were collected. The proportion of

7 FN, severe infection, categories of microorganisms and outcomes were compared between the

8 two groups. The presumed gateway of the infection was a posteriori considered and

9 evaluated.

Results: We analysed 1197 FN episodes (mean age: 8 years). $66 \%$ of the FN episodes occurred in children with blood cancer. Severe infections were identified in $23.4 \%$ of episodes overall. The rate of severe infection (28.4\% vs. $10.4 \%)$, types of microorganisms and the need for a management in intensive care unit ( $2.6 \%$ vs. $0.5 \%)$ was significantly different between children with blood cancer and solid tumor. Digestive or respiratory presumed gateway of the infections was less frequent for patients with solid tumor.

Conclusion: Given these important microbiological and clinical differences, it may be appropriate to consider differently the risk of severe infection in these two populations and therefore the management of FN. 


\section{Introduction}

Treatment protocols for childhood cancer have changed in last decades: intensified therapy, combined with improved supportive care, have both contributed to the current 5-year survival rate, which exceeds $70 \%$ for all cancers combined [1,2]. A first consequence of this improvement is the increase in the number and duration of episodes of febrile neutropenia (FN) and the increased risk of infectious complications [3]. Episodes of FN are thus among the most frequent complications and causes of hospitalization in children treated with chemotherapy [4]. At the same time, severe infections have been shown to be present in only $10-29 \%$ of $\mathrm{FN}$ cases [5-8], with mortality rates due to infectious complications of $\mathrm{FN}$ episodes reduced to less than 0.25 to $0.75 \%$ in high-income countries [6,9].

For those reasons, a change has been proposed since 2012 by an international panel of experts in FN management and updated in 2017 [10,11]. The idea was to propose a management based on the risk of severe infection, in order to avoid a systematic intensive management for all children with FN, which was a risk factor for in-hospital complications, emergence of antimicrobial resistances [12,13], impairment of the quality of family life $[14,15]$, and increased medical costs $[16,17]$. The clinical decision rules proposed in these guidelines to stratify the risk of severe infection, have however limited reproducibility in external sets of patients $[18,19]$. These rules concern all patients regardless of the type of cancer. We have shown previously that the type of cancer (i.e., blood cancer or solid tumor) was a variable significantly associated with the risk of severe infection [20]: the infectious complications were less frequent in children with solid tumors than in children with blood cancers, probably because of differences in protocols of chemotherapy. Consequently, one assumption to improve these rules could be to differentiate FN management based on the type of cancer. 
patients treated for solid tumor and blood cancer appear to be sufficiently important to consider the type cancer as a discriminating variable that should be initially considered for the management of FN in children.

\section{Methods}

52

\subsection{Study design and patients}

Since April 2007 to April 2016, all consecutive episodes of FN were prospectively collected in two centers in Lille, France (Pediatric hematology, Lille University Hospital and pediatric oncology, Oscar Lambret Cancer Centre, Lille). These two centers maintained the same recruitment over the study period and were the only reference centers for treatment of children with cancer in the Northern France area, where one million children were living in 2012 [21]. Throughout the duration of the study these two centers followed the national recommendations for the treatment of cancer from the French society against cancer in children and teenagers (SFCE). Each patient aged less than 18 years who had a chemotherapy-induced FN episode was included. Patients were not included if they were being treated for an infection, received palliative care, or had undergone a stem cell transplantation.

\subsection{Data collected}

Data were collected using a standardized case report form completed at the time of each FN episode. Age, sex, type of cancer, high risk of deep and prolonged chemotherapy-induced aplasia, relapse of oncologic disease and all data needed for the diagnosis of infections, including the diagnosis of severe infections (see definitions) were collected.

\subsection{Definitions}


FN was defined by neutrophil count $<500 / \mathrm{mm}^{3}$ or a neutrophil count $<1000 / \mathrm{mm}^{3}$ that tends to drop under $500 / \mathrm{mm}^{3}$ in the following 48 hours [5], and an adjusted axillary temperature $\geq 38.5^{\circ} \mathrm{C}$ once or $\geq 38.0^{\circ} \mathrm{C}$ twice within 12 hours. High risk of deep and prolonged chemotherapy-induced aplasia was defined by a neutropenia lasting for more than seven days as previously defined [22,23]. Severe infection was defined by the occurrence of either (i) a bacteremia, or (ii) bacterial infection, or (iii) focal infection at high risk of dissemination, or (iv) an invasive fungal infection [20]. Bacteremia was defined by a positive blood culture, except in cases of infection with coagulase-negative staphylococci or other contaminant microorganisms, for which two positive blood cultures were required. Bacterial infection was defined by positive bacterial culture from a normally sterile site. Focal infection at high risk of dissemination was defined as any local infection with or without microbiological documentation into a normally sterile site, with significant risk of loco-regional or systemic spread (e.g. pelvic cellulitis, rapidly progressive cellulitis, appendicitis, pneumonia). Invasive fungal infection is referred to a proven, probable, or possible fungal infection as defined by the IFICG (Invasive Fungal Infections Cooperative Group) of the EORTC (European Organization for Research and Treatment of Cancer) [24].

The management of FN episodes and the treatment of documented infections were homogeneous between the two centers. It followed the guidelines established in the units by the same team of pediatric infectious disease physicians in the Lille University Hospital, adapted in 2013 on the basis of the 2012 pediatric guidelines published for the management of fever and neutropenia [10]. Severe infections were divided into four microbiological categories: gram-negative bacilli infection, gram-positive cocci infection, fungal infection, and any other type of infection. The presumed gateway of the infection was determined $a$ posteriori with the type of clinical infection and microbiological documentation by two 
pediatric infectious diseases experts and classified into six categories: oral, digestive, cutaneous-catheter, respiratory, urinary or other gateway.

\subsection{Statistical analyses}

The population of included patients was first described. Then, qualitative variables were compared using chi-square test. Continuous variables were compared using a Student's $t$ test. A $p$ value of less than 0.05 was considered statistically significant. Statistical analyses were performed using SPSS package version 22 software.

This prospective, observational research was validated by the French ethic committee for observational studies: "comité consultatif sur le traitement de l'information en matière de recherche dans le domaine de la santé" and "commission nationale de l'informatique et des libertés”, reference: DEC20081118-0010.

\section{Results}

From April 2007 to April 2016, 1197 episodes of FN were collected (mean age 8.0 years $( \pm 5.0)$, male/female ratio: 1.25$)$. The inclusion rate by year according to the type of tumor and the presence or not of severe infection was presented in Figure 1. The rate of severe infection according to the tumor is presented Table I. The chemotherapy used was at high risk of deep and prolonged neutropenia for 808 episodes of FN (68\%), $69 \%$ in children treated for blood cancer and $64 \%$ in children treated for solid tumor (Table II). The FN episode occurred in a context of disease relapse in 148 cases (12\%). A severe infection was diagnosed in $267 \mathrm{FN}$ episodes (22\%, 95\% CI: $20-25)$ statistically more frequently in patients with blood cancer (p $\left.<10^{-5}\right)$ (Table II). Twenty-three cases $(2 \%, 95 \% \mathrm{CI}$ : 1-3) were transferred in the intensive care unit (ICU) with a rate significantly higher for FN episodes in patients with blood cancer. The mortality rate was of $0.4 \%$ (95\% CI: $0.2-1.0)$, with five FN-related death in patients treated for blood cancer and none in patients treated for solid tumor $(\mathrm{p}=0.13)$. 
A microbiological documentation was found in $207 \mathrm{FN}$ (17\% of FN episodes; $78 \%$ of

FN with severe infection). The microorganisms identified are presented by category in Table III. Globally, categories of microorganisms identified were statistically different between FN occurring in patients with solid tumor or blood cancer $\left(\mathrm{p}<10^{-5}\right)$. The presumed gateway of the infection was statistically different between FN occurring in patients with solid tumor or blood cancer (Table II). Severe infections without microbiological documentation $(n=60$, including 52 with blood cancer) were: pneumonia $(n=27)$, cellulitis $(n=11)$, probable aspergillosis $(n=11)$, appendicitis $(n=7)$, septic shock $(n=3)$, acute colitis $(n=1)$.

\section{Discussion}

Statistically significant differences in the rates and severity of infections were found between children with FN treated for solid tumor or blood cancer. Patients treated for blood cancer presented severe infections more frequently (28\%) than those treated for solid tumor (10\%) and had a higher ICU admission rate (2.6 vs. $0.2 \%)$. The presumed gateway of their infection was more often through the oral or lower respiratory tract. The presumed gateway of infection was more often cutaneous or catheter related for patients with a solid tumor. The distribution of types of microorganisms identified was globally statistically different between patients with blood cancer and solid tumor.

There were sparse data of these differences. Indeed, our study was one of the first to analyze the differences in terms of infections between patient treated for solid tumor and blood cancer with chemotherapy-induced FN. In 2002, some authors found no difference in the amount of infection according to the type of cancer but bacteremia and pneumonia were more frequent in patients treated for blood cancer, particularly for leukemia [25].

Contradictory results were described in adult patients with cancer. In 2013, a study found that patients treated for blood cancer had more gram-negative bacilli bacteremia than patients with 
solid tumor [26]. But another study found more infections in patients with solid tumor [27].

However the cancer types and treatments were too different between adults and children to compare infectious events between the two populations [28].

There may be multiple reasons for these differences. First, the type of cancer is probably not directly responsible for these differences, but more likely the chemotherapy drugs used [29]. At that time, some drugs were used quasi-exclusively for solid tumors and other drugs for blood cancers, with different targets. Chemotherapy drugs are usually more myeloablative with a more prolonged FN for blood cancer than for solid tumors. Second, when a similar treatment was used for both types of cancer, the doses and rates of administration were very different. The impact on the gut and thus on the risk of microbial translocation was therefore totally different. Third, the type of central venous access may have played a role. Catheter risks may vary depending on the type of central venous catheter or how it is managed. It was impossible to analyze this data in this study, because the population was nearly homogeneous: the patients treated for solid tumors had almost always an implantable catheter chamber, whereas patients treated for a blood cancer had almost always a tunneled central venous catheter $\left(\right.$ Broviac $\left.^{\circledR}\right)$.

Although the data were from only two centers, our series $(n=1197$ episodes of $F N)$ is one of the largest prospective cohorts of FN in children. Even if the distribution of microorganisms was statistically different between the two groups, the number of patients was not enough to show a difference by types of microorganisms involved, which is suspected. Patients with blood cancer and solid tumor were treated in separate centers, but these centers are not very far apart and work in close collaboration with similar strategies for infectious diseases management decided by the same pediatric infectious disease unit. The recruitment within these two centers was carried out in the same region of Northern France. The prospective collection has ensured a high quality and homogeneity of these data. In our 
study, the choice was made, like others $[6,30,31]$ to predict severe infection rather than bacteremia only, in order to consider all infectious events at risk of complication. This also seemed more applicable in clinical practice. One patient may have been included several times at each FN episode. This was not inconvenient since we showed in a previous work, using a generalized mixed model, that the multiple inclusion of a single patient had no impact [20]. It also seemed more logical to consider all episodes from a clinical practice perspective, where the infectious risk is assessed at each FN episode and not only at the first.

The proportion of each type of cancer and identified microorganisms in patients with severe infections were roughly similar to other studies on FN in children [30]. Some centers had a higher proportion of gram-positive cocci [31] but with different proportion in the type of tumor (less lymphoid leukemia). The predominance of gram-positive cocci in other studies may be due to single CoNS positive blood cultures, considered as contaminants in this research and in our clinical practice [29]. In 2013, Miedema et al. found also a majority of gram-positive cocci in three centers. It could be explained by the use of prophylactic antigram-negative antibiotics, particularly in one center, with the consequence of a higher resistances rate [32].

\section{Conclusion}

The physicians who manage those children with cancer are aware from experience that the risk of severe infection seems different. However, therapeutic protocols are usually not differentiated. Surprisingly, only a few clinical decision makers have identified the type of cancer as a differential risk of severe infection $[8,20,33,34]$. But the differences in terms of infections between patients with blood cancer and solid tumor have never been as widely analyzed as here. The strong differences shown here confirm the importance of the type of cancer as a useful variable for a differential management of children with FN. Our results 
would justify separating completely the patients treated for blood cancer and those treated for a solid tumor to propose two decision rules predicting severe infection in children with FN. Currently, the management of FN is heterogeneous from one center to another, even within the same country [35]. Since the publication of the international guidelines for FN in children in 2012 [10], updated in 2017 [11], a work to propose standardized definitions and a relevant consensual core outcome has been launched [36]. However, the type of cancer is a variable considered in the risk assessment for severe infection in none of the six decision rules proposed in these guidelines. One possibility to take this variable into consideration could be to use a decision tree with a first division that could be the type of cancer. Given that the infection-related rate of mortality in children with solid tumor was zero in our large series and that the severity of infection during $\mathrm{FN}$ is rare (10\%) in this population, an outpatient management of these patients could be probably rapidly proposed for low-risk patients. Other criteria are also needed to propose an alternative management of patients with blood cancer at low-risk of severe infection.

\section{Financial support}

\section{None}

\section{Conflict of interests}

MD, RD, ML, FM, HD have no conflict of interest; AM has had appointments for lecture and consultancy/advice (GSK vaccines, Pfizer), and invitations to ESPID meetings (GSK vaccines, Pfizer); FD has been invited for a lecture without fees at the national pediatric primary-care meeting (AFPA) 2017 by GSK vaccines. He has received fees from Biocodex for two lectures in 2017 pediatric meetings.

\section{References}


[1] Pritchard-Jones K, Kaatsch P, Steliarova-Foucher E, Stiller CA, Coebergh JW. Cancer in children and adolescents in Europe: developments over 20 years and future challenges. 2006;42:2183-90.

221 htpps://DOI.org/10.1016/j.ejca.2006.06.006

222 [2] Gatta G, Botta L, Rossi S, Aareleid T, Bielska-Lasota M, Clavel J, et al. Childhood cancer 223 survival in Europe 1999-2007: results of EUROCARE-5--a population-based study. Lancet Oncol 2014;15:35-47. htpps://DOI.org/10.1016/S1470-2045(13)70548-5

[3] Pizzo PA, Rubin M, Freifeld A, Walsh TJ. The child with cancer and infection: I. Empiric therapy for fever and neutropenia, and preventive strategies. J Pediatr 1991;119:679-94. https://doi.org/10.1016/S0022-3476(05)80281-1

[4] Freyer G, Scotte F, Borget I, Bruyas A, Vainchtock A, Chouaid C. Clinical burden caused by hospitalization for febrile neutropenia in France in 2010-2011: An analysis of the PMSI database. Bull Cancer 2016;103:552-60. https://doi.org/10.1016/j.bulcan.2016.03.012

[5] Baorto EP, Aquino VM, Mullen CA, Buchanan GR, DeBaun MR. Clinical parameters associated with low bacteremia risk in 1100 pediatric oncology patients with fever and neutropenia. Cancer 2001;92:909-13. https://doi.org/10.1002/1097-0142(20010815)92:4<909::AID-CNCR1400>3.0.CO;2-H [6] Ammann RA, Bodmer N, Hirt A, Niggli FK, Nadal D, Simon A et al. Predicting adverse events in children with fever and chemotherapy-induced neutropenia: the prospective multicenter SPOG 2003 FN study. 2010 J Clin Oncol 28:2008-14. 
[7] Badiei Z, Khalesi M, Alami MH, Kianifar HR, Banihashem A, Farhangi H, et al. Risk

factors associated with life-threatening infections in children with febrile neutropenia: a data mining approach. J Pediatr Hematol Oncol 2011;33:e9-e12. https://doi.org/10.1097/MPH.0b013e3181f6921a.

[8] Hakim H, Flynn PM, Srivastava DK, , Knapp KM, Li C, Okuma J et al. Risk prediction in 246 pediatric cancer patients with fever and neutropenia. Pediatr Infect Dis J 2010;29:53-9. https://doi.org/10.1097/INF.0b013e3181c3f6f0 introduction and audit of a step-down oral antibiotic strategy for low risk paediatric febrile neutropaenia in a UK, multicentre, shared care setting. Eur J Cancer 2009;45:2843-9. https://doi.org/10.1016/j.ejca.2009.06.003 for the management of fever and neutropenia in children with cancer and/or undergoing hematopoietic stem-cell transplantation. J Clin Oncol 2012;30:4427-38.

256 [11] Lehrnbecher T, Robinson P, Fisher B, Alexander S, Ammann RA, Beauchemin M et al.

257 Guideline for the management of fever and neutropenia in children with cancer and hematopoietic stem-cell transplantation recipients: 2017 update. J Clin Oncol 2017;35:208294.

261 [12] Irfan S, Idrees F, Mehraj V, Habib F, Adil S, Hasan R. Emergence of carbapenem 262 resistant gram negative and vancomycin resistant gram positive organisms in bacteremic 263 isolates of febrile neutropenic patients: a descriptive study. BMC Infect Dis 2008;8:80. https://doi.org/10.1186/1471-2334-8-80 
[13] Mikulska M, Viscoli C, Orasch C, Livermore DM, Averbuch D, Cordonnier C, et al. 266 Fourth european conference on infections in leukemia group (ECIL-4), a joint venture of

EBMT, EORTC, ICHS, ELN and ESGICH/ESCMID aetiology and resistance in bacteraemias among adult and paediatric haematology and cancer patients. J Infect 2014;68:321-31. https://doi.org/10.1016/j.jinf.2013.12.006

[14] Sung L, Feldman BM, Schwamborn G, Paczesny D, Cochrane A, Greenberg ML, et al. Inpatient versus outpatient management of low-risk pediatric febrile neutropenia: measuring parents and healthcare professionals’ preference. J Clin Oncol 2004;22:3922-9. https://doi.org/10.1200/JCO.2004.01.077

[15] Cheng S, Teuffel O, Ethier M.C, Diorio C, Martino J, Mayo C, et al. Health-related quality of life anticipated with different management strategies for paediatric febrile neutropaenia. Br J Cancer 2011;23:606-11.

https://doi.org/10.1038/bjc.2011.213

[16] Raisch DW, Holdsworth MT, Winter SS, Hutter JJ, Graham ML. Economic comparison of home-care-based versus hospital-based treatment of chemotherapy-induced febrile neutropenia in children. Value Health 2003;2:158-66.

https://doi.org/10.1046/j.1524-4733.2003.00219.x

[17] Elting LS, Lu C, Escalante CP, Giordano SH, Trent JC, Cooksley C, et al. Outcomes and cost of outpatient or inpatient management of 712 patients with febrile neutropenia. J Clin Oncol 2008;26:606-11.

https://doi.org/10.1200/JCO.2007.13.8222

[18] Macher E, Dubos F, Garnier N, Delebarre M, De Berranger E, Thebaud E, et al. Predicting the risk of severe bacterial infection in children with chemotherapy-induced febrile neutropenia. Pediatr Blood Cancer 2010;55:662-7.

https://doi.org/10.1002/pbc.22586 
[19] Miedema KG, de Bont ES, Oude Nijhuis CS, van Vliet D, Kamps WA, Tissing WJ. Validation of a new risk assessment model for predicting adverse events in children with fever and chemotherapy-induced neutropenia. J Clin Oncol 2011;29:e182-4.

https://doi.org/10.1200/JCO.2010.32.7767

[20] Delebarre M, Garnier N, Macher E, Thebaud E, Mazingue F, Leblond P, et al. Which variables are useful for predicting severe infection in children with febrile neutropenia? $\mathrm{J}$

Pediatr Hematol Oncol 2015;37:e468-74.

https://doi.org/10.1097/MPH.0000000000000440.

[21] Insee flash $n^{\circ} 4$ January 2015.

https://www.insee.fr/fr/statistiques/1285215 [accessed 05 october 2018]

[22] Castagnola E, Fontana V, Caviglia I, Caruso S, Faraci M, Fioredda F, et al. A prospective study on the epidemiology of febrile episodes during chemotherapy induced neutropenia in children with cancer or after hemopoietic stem cell transplantation. Clin Infect Dis 2007;45:1296-304.

https://doi.org/10.1086/522533

[23] Werba BE, Hobbie W, Kazak AE, Ittenbach RF, Reilly AF, Meadows AT, et al. Classifying the intensity of pediatric cancer treatment protocols: the intensity of treatment rating scale 2.0 (ITR-2). Pediatr Blood Cancer 2007;48, 673-67.

https://doi.org/10.1002/pbc.21184

[24] De Pauw B, Walsh TJ, Donnelly JP, Stevens DA, Edwards JE, Calandra T, et al. Revised definitions of invasive fungal disease from the European Organization for Research and Treatment of Cancer/Invasive Fungal Infections Cooperative Group and the National Institute of Allergy and Infectious Diseases Mycoses Study Group (EORTC/MSG) Consensus Group. Clin Infect Dis 2008;46:1813-21.

https://doi.org/10.1086/588660 
[25] Koçak U, Rolston KV, Mullen CA. Fever and neutropenia in children with solid tumors is similar in severity and outcome to that in children with leukemia. Support Care Cancer 2002;10:58-64.

https://doi.org/10.1007/s005200100277

[26] Samonis G, Vardakas KZ, Maraki S, Tansarli GS, Dimopoulou D, Kofteridis DP, et al. Prospective study of characteristics and outcomes of bacteremia in patients with solid organ or hematologic malignancies. Support Care Cancer 2013;21:2521-6. https://doi.org/10.1007/s00520-013-1816-5

[27] Marin M, Gudiol C, Ardanuy C, Tansarli GS, Dimopoulou D, Kofteridis DP, et al.

Bloodstream infections in neutropenic patients with cancer: Differences between patients with haematological malignancies and solid tumours. J Infect 2014;69: 417-23. https://doi.org/10.1007/s00520-013-1816-5

[28] Marín M, Gudiol C, Ardanuy C, Garcia-Vidal C, Jimenez L, Domingo-Domenech E, et al. Factors influencing mortality in neutropenic patients with haematologic malignancies or solid tumours with bloodstream infection. Clin Microbiol Infect 2015;21:583-90. https://doi.org/10.1016/j.cmi.2015.01.029

[29] Sung L, Gamis A, Alonzo TA, Buxton A, Britton K, Deswarte-Wallace J, et al. Infections and association with different intensity of chemotherapy in children with acute myeloid leukemia. Cancer 2009;115:1100-8.

https://doi.org/10.1002/cncr.24107

[30] Santolaya ME, Alvarez AW, Avoles CL, Becker A, Cofré J, Enríquez N, et al. Prospective evaluation of a model of prediction of invasive bacterial infection risk among children with cancer, fever, and neutropenia. Clin Infect Dis 2002;35:678-83. https://doi.org/10.1086/342064 
[31] Santolaya ME, Alvarez AM, Aviles CL, Becker A, King A, Mosso C, et al. Predictors of severe sepsis not clinically apparent during the first twenty-four hours of hospitalization in children with cancer, neutropenia, and fever: a prospective, multicenter trial. Pediatr Infect

342

Dis J 2008; 27:538-43.

https://doi.org/10.1097/INF.0b013e3181673c3c

[32] Miedema KG, Winter RH, Ammann RA, , Droz S, Spanjaard L, de Bont ES, et al. Bacteria causing bacteremia in pediatric cancer patients presenting with febrile neutropeniaspecies distribution and susceptibility patterns. Support Care Cancer 2013;21:2417-26. https://doi.org/10.1007/s00520-013-1797-4

[33] Paganini H, Caccavo J, Aguirre C, Gómez S, Zubizarreta P. A scoring system to predict superinfections in high-risk febrile neutropenic children with cancer. Bol Med Hosp Infant Mex 2011;68:36-43.

https://www.researchgate.net/publication/262475795_A_scoring_system_to_predict_superinf ections_in_high-risk_febrile_neutropenic_children_with_cancer

[34] Phillips RS, Sung L, Ammann RA, Riley RD, Castagnola E, Haeusler GM' et al. Predicting microbiologically defined infection in febrile neutropenic episodes in children: global individual participant data multivariable meta-analysis. Br J Cancer 2016;114:e17. https://doi.org/10.1038/bjc.2016.28

[35] Delebarre M, Tiphaine A, Martinot A, Dubos F. Risk-stratification management of febrile neutropenia in pediatric hematology-oncology patients: Results of a French nationwide survey. Pediatr Blood Cancer 2016;63:2167-72.

https://doi.org/10.1002/pbc.26121

[36] Haeusler GM, Phillips RS, Lehrnbecher T, Thursky KA, Sung L, Ammann RA. Core outcomes and definitions for pediatric fever and neutropenia research: a consensus statement from an international panel. Pediatr Blood Cancer 2015;62:483-9. 
364 https://doi.org/10.1002/pbc.25335

365 
366 Fig 1. Rate of inclusion by year between 2007 and 2016 with or without severe infection for children treated for blood cancer or solid tumor

$368 \mathrm{n}$, total of inclusion of febrile neutropenia cases each year; SI-, episodes of febrile neutropenia without severe infection; SI+, episodes of febrile neutropenia with severe infection

370 Inclusion from April to December 2007*

371 Inclusion from January to April 2016**

372

373 
374 Table 1. Rate of episodes of febrile neutropenia with severe infection in children according to 375 the type of cancer (2007-2016)

\begin{tabular}{|c|c|c|c|c|}
\hline \multirow[t]{3}{*}{ Type of cancer } & \multirow{3}{*}{$\begin{array}{c}\text { Total } \\
(\mathrm{n}=1197)\end{array}$} & \multirow{2}{*}{\multicolumn{3}{|c|}{$\begin{array}{l}\text { FN with severe infection } \\
\qquad(\mathrm{n}=267)\end{array}$}} \\
\hline & & & & \\
\hline & & $\mathrm{n}$ & $\%$ & $95 \% \mathrm{CI}$ \\
\hline ALL & 481 & 129 & 27 & $23-31$ \\
\hline AML & 163 & 62 & 38 & $31-46$ \\
\hline Lymphoma & 141 & 32 & 23 & $17-30$ \\
\hline Histiocytosis & 8 & 2 & 25 & $7-59$ \\
\hline Bone tumor & 169 & 18 & 11 & $7-16$ \\
\hline Neuroblastoma & 82 & 11 & 13 & $2-22$ \\
\hline Brain tumor & 46 & 3 & 6 & $2-17$ \\
\hline Rhabdomyosarcoma & 38 & 2 & 5 & $1-17$ \\
\hline Kidney tumor & 21 & 4 & 19 & $8-40$ \\
\hline Rhabdoid tumor & 19 & 4 & 21 & $9-43$ \\
\hline Others & 29 & 0 & 0 & $0-11$ \\
\hline \multicolumn{5}{|c|}{$\begin{array}{l}\text { FN: febrile neutropenia; CI: confidence interval; ALL: Acute Lymploïd Leukemia; AML: Acute Myeloïd } \\
\text { Leukemia }\end{array}$} \\
\hline
\end{tabular}


383 Table 2. Infectious differences between children with blood cancer and solid tumor

\begin{tabular}{|c|c|c|c|}
\hline Variables & $\begin{array}{l}\text { Blood cancer } \\
(n=793)\end{array}$ & $\begin{array}{l}\text { Solid tumor } \\
(n=404)\end{array}$ & $\mathbf{p}$ \\
\hline Mean age, in years (+/-SD) & $8.0(+/-4.6)$ & $8.2(+/-5.4)$ & 0.86 \\
\hline Male/Female ratio & 1.37 & 1.05 & 0.03 \\
\hline $\begin{array}{l}\text { High risk of deep and prolonged } \\
\text { neutropenia, n }(\% ; 95 \% \mathrm{CI})\end{array}$ & 549 & 259 & 0.07 \\
\hline Bacteremia (\%) & 126 & 24 & $<10^{-5}$ \\
\hline Severe infections, $\mathrm{n}(\% ; 95 \% \mathrm{CI})$ & 225 & 42 & $<10^{-5}$ \\
\hline Infection related ICU admission & 21 & 2 & 0.01 \\
\hline Infection related death & 5 & 0 & 0.13 \\
\hline Types of microorganisms $^{a}$ & & & $<10^{-5}$ \\
\hline$G N B(\%)$ & $97(43)$ & $15(36)$ & 0.37 \\
\hline$G P C(\%)$ & $57(24)$ & $15(36)$ & 0.16 \\
\hline Fungi $(\%)$ & $21(10)$ & $1(2)$ & 0.12 \\
\hline Others (\%) & $50(23)$ & $11(26)$ & \\
\hline Presumed gateway of the infection ${ }^{a}$ & & & $<10^{-5}$ \\
\hline Oral $(\%)$ & $40(18)$ & $1(2)$ & 0.01 \\
\hline Digestive (\%) & $94(42)$ & $16(38]$ & 0.77 \\
\hline Cutaneous or catheter (\%) & $17(7)$ & $15(36)$ & $<10^{-5}$ \\
\hline Lower Respiratory tract (\%) & $46(20)$ & $3(7)$ & 0.04 \\
\hline Urinary tract $(\%)$ & $24(11)$ & $6(15)$ & 0.49 \\
\hline Others (\%) & $4(2)$ & $1(2)$ & \\
\hline
\end{tabular}

FN, febrile neutropenia; SD, Standard deviation; GNB, gram negative bacilli; GPC, gram positive cocci; ICU, Intensive care Unit

${ }^{\mathrm{a}} \mathrm{chi}-2$ or fisher exact test calculated with dichotomous variables. For example: GNB versus all others types of microrganisms 
Table 3. Microorganisms identified in severe infections of children with chemotherapyinduced febrile neutropenia and site of identification (2007-2016)

\begin{tabular}{|c|c|c|c|c|c|c|c|}
\hline Microorganisms & $\begin{array}{l}\text { Blood Cancer } \\
n=173\end{array}$ & $\begin{array}{l}\text { Solid Tumor } \\
\mathrm{n}=34\end{array}$ & Blood & Urine & $B A L$ & Stool & Others \\
\hline$\overline{\text { GPC }(n=72)}$ & 57 & 15 & & & & & \\
\hline Staphylococcus aureus & 6 & 2 & 7 & & & & 1 (catheter) \\
\hline CoNS & 9 & 13 & 22 & & & & \\
\hline Streptococcus $\dagger$ & 36 & & 35 & & 1 & & \\
\hline Enterococcus & 4 & & & 3 & & & 1 (biopsy) \\
\hline Rothia musilaginosa & 2 & & 2 & & & & \\
\hline GNB $(n=110)$ & 95 & 15 & & & & & \\
\hline Escherichia coli & 54 & 12 & $49 *$ & 19 & & & 1 (biopsy) \\
\hline Pseudomonas & 21 & 2 & $17 * *$ & 5 & 1 & & \\
\hline Klebsiella & 11 & & 5 & 6 & & & \\
\hline Enterobacter & 3 & 1 & 3 & & & & 1 (peritoneal) \\
\hline Campylobacter & 2 & & & & & 2 & \\
\hline Others GNB & 4 & & 4 & & & & \\
\hline Anaerobes $(n=2)$ & 2 & & & & & & \\
\hline Captocytophaga sputi $\$$ † & 2 & & 2 & & & & \\
\hline Fungi $(n=11)$ & 10 & $\mathbf{1}$ & & & & & \\
\hline Candida & 5 & 1 & 4 & & 1 & & \\
\hline Mucor & 1 & & & & 1 & & \\
\hline Fusarium & 1 & & & & & & 1 (biopsy) \\
\hline Aspergillus & 3 & & & & & & 3 (antigens) \\
\hline Others $(n=12)$ & 9 & 3 & & & & & \\
\hline Neisseria & 4 & & 4 & & & & \\
\hline Lactococcus lactis & 1 & & 1 & & & & \\
\hline Clostridium & 1 & 3 & & & & 4 & \\
\hline Mycobacterium tuberculosis & 1 & & & & 1 & & \\
\hline Pneumocystis & 2 & & & & 2 & & \\
\hline
\end{tabular}

BAL, Broncho alveolar lavage; FN, febrile neutropenia; GNB, gram negative bacilli; GPC, gram positive cocci; $\mathrm{Ag}$, galactomannan; CoNS, coagulase negative Staphylococcus; other GNB, Moraxella, Aeromonas hydophila * 3 patients with blood culture and urinary culture positive, and 3 patients with blood culture positive to another microorganism: 1 Streptococcus, 1 Klebsiella, 1 Entocococcus. 


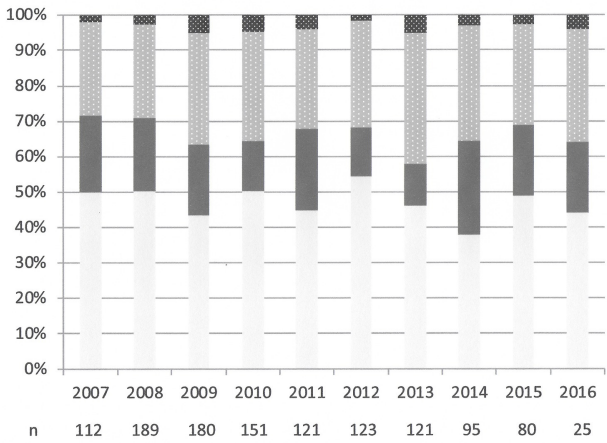

solid tumor SI+

(n) solid tumor SI-

- blood cancer SI+ blood cancer SI- 